\title{
The characteristics of lightning risk and zoning in Beijing simulated by a risk assessment model
}

\author{
H. Hu${ }^{1}$, J. Wang ${ }^{2}$, and J. Pan ${ }^{2}$ \\ ${ }^{1}$ Institute of Urban Meteorology, CMA, Beijing, China \\ ${ }^{2}$ Beijing Meteorological Bureau, Beijing, China
}

Correspondence to: $\mathrm{H}$. Hu (hbhu@ium.cn)

Received: 7 February 2013 - Published in Nat. Hazards Earth Syst. Sci. Discuss.: 16 August 2013

Revised: 17 May 2014 - Accepted: 4 June 2014 - Published: 6 August 2014

\begin{abstract}
In this study, the cloud-to-ground (CG) lightning flash/stroke density was derived from the lightning location finder (LLF) data recorded between 2007 and 2011. The vulnerability of land surfaces was then assessed from the classification of the study areas into buildings, outdoor areas under the building canopy and open-field areas, which makes it convenient to deduce the location factor and confirm the protective capability. Subsequently, the potential number of dangerous lightning events at a location could be estimated from the product of the CG stroke density and the location's vulnerability. Although the human beings and all their material properties are identically exposed to lightning, the lightning casualty risk and property loss risk was assessed respectively due to their vulnerability discrepancy. Our analysis of the CG flash density in Beijing revealed that the valley of JuMaHe to the southwest, the ChangPing-ShunYi zone downwind of the Beijing metropolis, and the mountainous PingGu-MiYun zone near the coast are the most active lightning areas, with densities greater than 1.5 flashes $\mathrm{km}^{-2}$ year ${ }^{-1}$. Moreover, the mountainous northeastern, northern, and northwestern rural areas are relatively more vulnerable to lightning because the high-elevation terrain attracts lightning and there is little protection. In contrast, lightning incidents by induced lightning are most likely to occur in densely populated urban areas, and the property damage caused by lightning here is more extensive than that in suburban and rural areas. However, casualty incidents caused by direct lightning strokes seldom occur in urban areas. On the other hand, the simulation based on the lightning risk assessment model (LRAM) demonstrates that the casualty risk is higher in rural areas, whereas the property loss risk is higher in urban areas, and this conclusion is also supported by the historical casualty and damage reports.
\end{abstract}

\section{Introduction}

Lightning severely threatens the safety of human beings and their property (Elsom, 1993, 2001; Holle et al., 1996, 2005; Curran et al., 2000; Zhang et al., 2011) and has been recognized as one of the most dangerous natural disasters by the International Decade for Natural Disaster Reduction (IDNDR) (Ma et al., 2008). The impact of lightning is straightforward, in that anyone or anything that is struck by lightning can suffer casualties or damages (Curran et al., 2000). Obviously, the lightning risk is related to regional lightning activity, especially the cloud-to-ground (CG) flash density (Changnon, 1992; Baker, 1999; Williams, 2005). The lightning location finder (LLF) data and the data collected by the satellite remote sensor of the Optical Transient Detector (OTD) and the Lightning Imaging Sensor (LIS) are all available and can be used to deduce the lightning density and the associated climatic characteristics of lightning activity (Tao and Meng, 1996; Christian et al., 2003; Bovalo et al., 2012). Tao and Zhao (1993) summarized the temporal-spatial distribution of lightning in northern China using LLF data and concluded that lightning activity can be strongly influenced by topography. Christian et al. (2003) found that the annual flash count translates to an average of $44 \pm 5$ lightning flashes (intra-cloud, IC, and CG combined) worldwide every second. Obviously, determining the distribution of lightning density related to the lightning activity, which is essential in lightning risk assessment, is possible with the development of observatory techniques.

Lightning risk assessment can be used to determine where a lightning incident is most likely to occur, and thereby assist with the avoidance and mitigation of the impacts of lightning (Meyer et al., 2009). Theoretically, lightning disasters 
are thought to be the result of interactions between their causative factors and exposure (Kaplan and Garrick, 1981; Smith, 1996; Garrick, 2002). The CG flash/stroke density can be considered the direct cause of a lightning incident, as it is the main factor contributing to lightning risk (Fuquay et al., 1967; Lopez and Holle, 1997; Lopez et al., 1997; Bogdan and Burcea, 2010). On the other hand, the population and its properties are also recognized as the components of exposure to lightning, as the lightning risk is considerably influenced by the distribution of population density (Holle et al., 2005; Wisdom, 2009; Zhang et al., 2011).

Vulnerability is another crucial factor in lightning risk (Ashley and Gilson, 2009). To assess this vulnerability, it is appropriate to classify the land surface as either buildings, outdoor areas under a building canopy, or open-field areas because the protective capability and location factors that determine the susceptibility to lightning differ among these areas. Various methodologies should be used to determine the protective capability and location factors. In a building, for example, factors such as its elevation, geometrical shape and height all influence lightning attraction and affect the building's vulnerability to lightning (Rizk, 1994; Petrov and D'Alessandro, 2002; Ait-Amar and Berger, 2005). The use of geographical information systems (GIS) in lightning risk assessment is thus desirable to make it easier to locate these classified areas, estimate their ability to collect lightning, and assess the protective capability of individual building.

The lightning risk assessment model (LRAM) uses GIS to calculate the average annual number of dangerous lightning events (ANDLE), lightning casualty risk, and property loss risk, aiming to explore the characteristics of lightning risk and its zoning. The model also simulates the lightning risk through the parameterization of the CG flash/stroke density, vulnerability, and exposure to lightning. It should be noted that some critical factors associated with the lightning risk, such as human behaviour, location and activity, are very difficult to quantify and may be negligible (Renn, 1998). However, the LRAM is able to calculate the risk value by repeatedly modifying the input parameters in the simulation until the model performance is satisfactory. After all, the simulation demonstrates the hypothesis of the lightning risk recognition in urban and rural areas in which the lightning casualty risk is higher in rural areas, whereas the property loss risk is higher in urban areas (Holle et al., 1996, 2005; Curran et al., 2000; Elsom, 1993, 2001; Wisdom, 2009).

\section{Data description}

\subsection{The lightning location finder data}

The climatological data recorded at 20 meteorological stations in Beijing between 1961 and 2008 were used to count the annual number of thunder days from which the CG flash density can be obtained using an empirical formula (Price and Rind, 1993), because the annual number of thunder days indicates the regional lightning activity (Gabriel and Changnon, 1989). Generally, the thunder days are recorded immediately by a weather observer on hearing the first peal of thunder, but this approach obviously causes uncertainty (Changnon, 1992; Gabriel and Changnon, 1989). For this reason, the annual number of thunder days roughly reflects the lightning activity, and the converted CG flash density data would be unsuitable for risk assessment because of their low resolution and inherent uncertainty.

Consequently, we used LLF data, recorded by the Beijing Meteorology Bureau, to calculate the CG lightning density. The data are based on SAFIR (Système d'Alerte Foudre par Interférométrie Radioélectrique) data recorded in 2007 and on ADTD (a lightning detection network of the China Meteorological Administration) data from 2008 to 2011. In China, the SAFIR network consists of SAFIR3000 sensors, which use the VHF interferometric technique for angular localization of lightning discharge, of both IC and CG lightning flashes, complemented with wide-band low frequency (LF) which uses the time-of-arrival (TOA) technique to characterize the lightning flashes to ground. The sensors have a detection efficiency (i.e. the percentage of actual flashes observed by the network) estimated by the manufacturer at about $90 \%$. Orville et al. (1987) concluded that in areas covered by two or more direction finders, $70 \%$ of all lightning could be detected. There are three SAFIR detection stations in the Beijing area (Fig. 1), separated by distances of 126$145 \mathrm{~km}$, which allows an accuracy of lightning detection of $1-2 \mathrm{~km}$ in most areas.

The ADTD network consists of 232 sensors and the system uses the IMPACT method for lightning location, which combines the magnetic direction finding (MDF) and timeof-arrival (TOA) techniques (Bertram and Mayr, 2004). The overall detection efficiency of the ADTD system is assumed to be between 80 and $90 \%$, with a position error of less than $500 \mathrm{~m}$. There are five detection stations of ADTD around Beijing (Fig. 1), yielding a detection efficiency that is higher than most other areas in China.

It is noticeable that the missed lightning detection under current detection efficiency would bring about uncertainty in LLF data. The SAFIR and ADTD would underdetect 10$20 \%$ of the lightning flashes. Updating and/or adding the detection finders optimally in the two networks is maybe a plausible approach to improving the location accuracy and detection efficiency, which can consequently reduce uncertainty in LLF data. Moreover, a correction model is needed to eliminate the effect of missed lightning detection in the future (Anderson and Klugmann, 2014).

The SAFIR data provide (1) the latitude, longitude and altitude of the lightning strike, and (2) five types of lightning location discrimination, which are 0 : isolated point, 1 : start point, 2: midpoint, 3: end of IC lightning, 4: return stroke, and 5: subsequent CG lightning stroke, which makes it possible to select CG stroke records from the data sets. The ADTD 


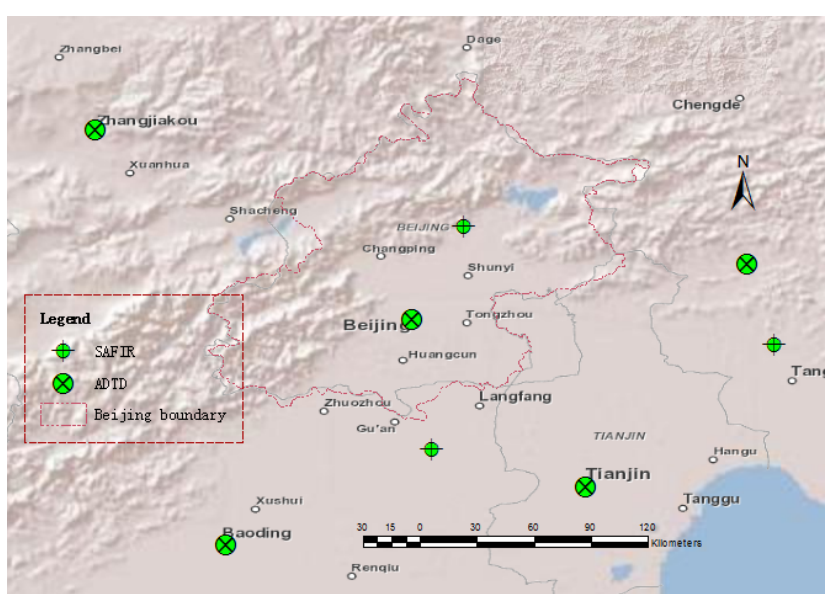

Figure 1. Distribution of SAFIR and ADTD detection stations around Beijing.

data provide the lightning latitude, longitude, intensity, slope, date time, and other features.

These detected CG return strokes had been grouped into CG flashes based on a multiplicity delay of $0.5 \mathrm{~s}$ within a radius of $7 \mathrm{~km}$ (Biagi et al., 2007; Cummins et al., 2006). All the +CG lightning flashes with peak currents of less than $15 \mathrm{kA}$ were classified as IC lightning (Cummins and Murphy, 2009). In total, in Beijing 54314 CG strokes detected by SAFIR in 2007 were grouped into $35171 \mathrm{CG}$ flashes, and ADTD detected 112144 CG flashes in four years, having an average multiplicity of 1.544 . It can be perceived that the average annual CG flash density is approximately 1.8 flashes $\mathrm{km}^{-2}$ year ${ }^{-1}$ in the $16370 \mathrm{~km}^{2}$ area around Beijing.

The CG lightning data had been mapped using GIS, and the number of CG flash/stroke points contained in each grid cell (see the following section for the definition of grid cell used here), taken to be the CG flash/stroke density, was counted by a GIS statistical operator. As the return stroke and its subsequent CG strokes of a CG flash lead to lightning casualties and damages respectively, it is preferable to use the stroke density to calculate ANDLE.

\subsection{The lightning casualties and damages reports}

The lightning casualties and damages reports from 2001 to 2010, provided by the Beijing Lightning Devices Security Test Center, were used to explain the characteristics of lightning disasters. For each incident, these reports provide the (1) date and time; (2) location; (3) number and location of fatalities/injuries; and (4) financial cost of any damage. A total of 440 lightning incidents, with 23 being casualty incidents, were recorded. The locations of these incidents were also mapped from the description in the reports. The incident distribution map partially reflects the lightning risk characteristics and may help with testing and comparison of the assessment results.

Other data were also used, including (1) the GIS data sets with a high spatial resolution of $1: 2000$ in urban settings and $1: 50000$ in rural settings, together with the buildings data set containing information regarding building type and number of floors, which is necessary for estimating the protective capability and the collection area of a building against lightning, which is related to its height; (2) a distribution map of population and GDP (i.e. the value of a country's overall output of goods and services (typically during one fiscal year) at market prices, excluding net income from abroad) density derived from the Beijing statistical yearbook published in 2007; and (3) the digital elevation map (DEM) with a resolution of $50 \mathrm{~m} \times 50 \mathrm{~m}$ used to determine the terrain features of the land surface.

The lightning risk assessment model (LRAM) is designed to perform on a GIS grid composed of $182 \times 181$ cells (Fig. 2), ranging from 115.3672 to $117.5213^{\circ} \mathrm{E}$ and from 39.4207 to $41.0714^{\circ} \mathrm{N}$, which covers the entire area of Beijing. The CG lightning flashes/strokes (fl/st), population (persons) and GDP (Yuan million) density were assigned to each $1 \mathrm{~km} \times 1 \mathrm{~km}$ grid cell. The model uses the input parameters together with the information abstracted from GIS data to simulate the lightning risk quantitatively, and to calculate the vulnerability value, casualty risk and property loss risk for each grid cell; then the gridded data would be validated for final risk mapping and zoning (see Figs. 7-10).

\section{The basic risk assessment formula}

Theoretically, the disaster risk value $R$ is considered to be the product of frequency $N$ and exposure $E$ (Smith, 1996), that is

$R=N \cdot E$,

where the exposure $E$ is usually substituted by population and properties, parameterized using the population and gross domestic product (GDP) densities, and $N$ is the frequency of dangerous lightning strikes, represented by the ANDLE $N_{x}$ $\left(\right.$ times year $^{-1}$ ), which is

$N_{x}=K \cdot N_{\mathrm{g}} \cdot A_{\mathrm{d}}$,

where $N_{\mathrm{g}}$ is the average annual CG stroke density, preferably obtained from the LLF data (Tao and Zhao, 1993; Zheng et al., 2005), $A_{\mathrm{d}}\left(\mathrm{m}^{2}\right)$ the equivalent collection area to lightning, and $K$ is the correction factor, denoting the vulnerability involving protection measures and susceptibility to lightning.

\section{The method of calculating ANDLE}

Classifying the land surface into buildings, outdoor areas under a building canopy and open-field areas is necessary when 


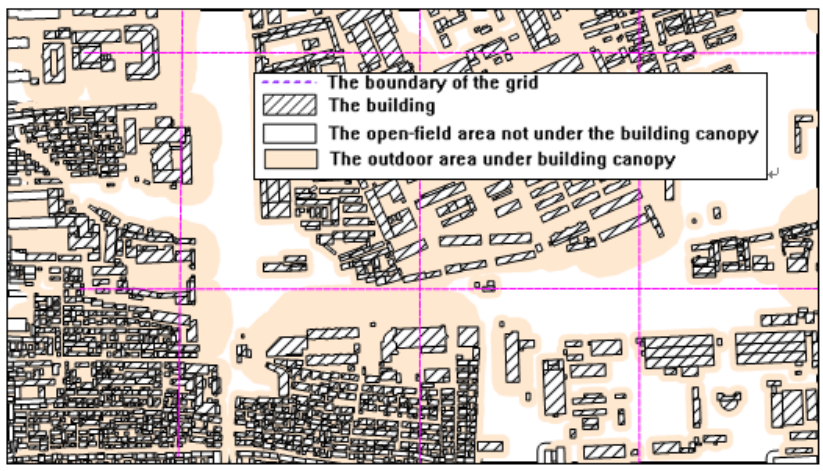

Figure 2. Classification of the buildings, outdoor areas under a building canopy and open-field areas on the land surface and its samples in the grid cells.

calculating ANDLEs, given the convenience of measuring the collection areas of an object to lightning using certain geometrical shapes or heights of structures, and estimating the location factors using the elevation of structures. Additionally, confirming the protective capability by the classification is favourable for distinguishing the capability discrepancies in individual buildings. The classification also simplifies the model parameterization when calculating the number of dangerous lightning events, which can be accomplished on the GIS grid. Figure 2 contains examples of the classified areas and the GIS grid cells.

\subsection{Estimating average ANDLEs of buildings}

In built-up areas, the ANDLE of a building $N_{\mathrm{d}}\left(\right.$ times year $\left.^{-1}\right)$ can be estimated as follows:

$N_{\mathrm{d}}=N_{\mathrm{g}} \cdot A_{\mathrm{d}} \cdot C_{\mathrm{d}} \cdot P_{\mathrm{d}} \times 10^{-6}$,

where $A_{\mathrm{d}}\left(\mathrm{m}^{2}\right)$ is the collection area of a building to lightning, $C_{\mathrm{d}}$ the location factor, and $P_{\mathrm{d}}$ is the protective factor. Except for the CG stroke density, $N_{\mathrm{g}}$, obtained from the LLF data, the other parameters can be determined as follows.

\subsubsection{The collection area of a building to lightning}

The capacity of a building to collect lightning depends on its location, height and the influence of the nearby buildings. Fundamentally, the dimension of a collection area is assumed to be three times the building height (IEC62305, 2006). However, this area may intersect with that of the other buildings, and several cases may need to be taken into account when calculating collection areas.

The first case is a single building with no other buildings; thus its collection area does not intersect with that of any other buildings (Fig. 3a). In this case, the collection area is determined by the geometrical buffer of the building in which the distance from the buffer border to the building edge is three times the building height. (a)
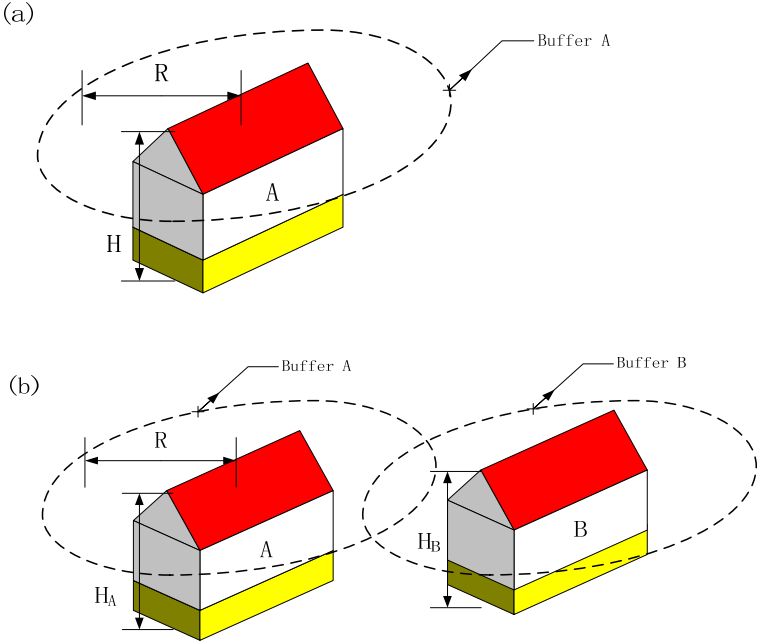

(c)

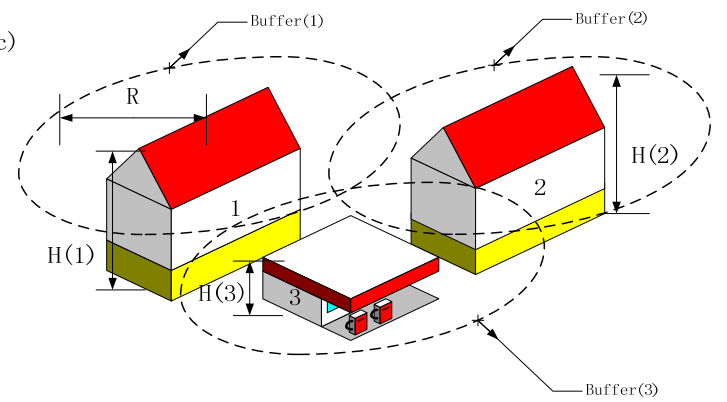

Figure 3. Schematic representations of (a) building A with its covering distance of collecting radius, and its collection area, buffer A; (b) two neighbouring buildings (A and B) and intersecting collection areas; and (c) more than two neighbouring buildings and their intersecting collection areas.

The second case is where the collection areas of two buildings intersect with each other (Fig. 3b). The allocation of the intersection area of the two buildings depends on the buildings' heights (Rizk, 1994), i.e. the higher building usually occupies a greater proportion of intersection area, which is

$$
\begin{aligned}
\begin{aligned}
A_{\mathrm{d}}(A)= & S_{\text {Buffer A }}-\left(1-\frac{H_{\mathrm{A}}}{H_{\mathrm{A}}+H_{\mathrm{B}}}\right) \cdot S_{\text {intersect }} \\
& =S_{\text {Buffer A }}-\left(\frac{H_{\mathrm{B}}}{H_{\mathrm{A}}+H_{\mathrm{B}}}\right) \cdot S_{\text {intersect }} \\
A_{\mathrm{d}}(B)= & S_{\text {Buffer B }}-\left(\frac{H_{\mathrm{A}}}{H_{\mathrm{A}}+H_{\mathrm{B}}}\right) \cdot S_{\text {intersect }}
\end{aligned}
\end{aligned}
$$

where $A_{\mathrm{d}}(\mathrm{A})$ and $A_{\mathrm{d}}(\mathrm{B})$ are the collection areas of buildings A and B, respectively (Fig. $3 \mathrm{~b}$ ), $S_{\text {Buffer A }}$ and $S_{\text {BufferB }}$ are the respective buffer areas, $H_{\mathrm{A}}$ and $H_{\mathrm{B}}$ are the respective building heights, and $S_{\text {intersect }}$ is the intersect area of buffers $\mathrm{A}$ and $\mathrm{B}$. If the heights $\mathrm{A}$ and $\mathrm{B}$ are equal, the intersection area will be allocated equally, implying that their capability to collect lightning is the same. 
The third case is where the collection areas of more than two buildings overlap with one another (Fig. 3c). Each collection area can then be calculated as follows:

$$
A_{\mathrm{d}}(1)=S_{\text {buffer }}(1)-\left(1-\frac{H(1)}{\sum_{i=1}^{n} H(i)}\right) \cdot S_{\text {overlap }}(1)
$$

$A_{\mathrm{d}}(n)=S_{\text {buffer }}(n)-\left(1-\frac{H(n)}{\sum_{i=1}^{n} H(i)}\right) \cdot S_{\text {overlap }}(n)$,

where $A_{\mathrm{d}}(1), \ldots$, and $A_{\mathrm{d}}(n)$ are the collection areas of buildings $1, \ldots$, and $n$, respectively, $S_{\text {Buffer(1) }}, \ldots$, and $S_{\text {Buffer }(n)}$ are the respective buffer areas, $S_{\text {overlap }}(1), \ldots$, and $S_{\text {overlap }}(n)$ are the respective overlapping areas of each building buffer with the others, and $H(1), \ldots$, and $H(n)$ are the respective building heights.

\subsubsection{Location factor of building}

The lightning attachment of a building is influenced to a degree by the topography of the building location, and primarily by its elevation within a range of $250 \mathrm{~m}$ (IEC62305, 2006), where a relatively higher location attracts more ground lightning flashes/strokes than its surroundings. Herein, the digital elevation map (DEM) is used to estimate the location factor value $C_{\mathrm{d}}$, which is determined by the surrounding topography (see IEC62305, 2006, Part 2, p. 97).

\subsubsection{Protective capability of building}

The protective capability of a building includes (1) the ability to protect the live beings from being injured by a lightning stroke, (2) protecting the building itself from physical damage, and (3) protecting the internal systems of the building. In risk estimation, these protective capabilities are represented by the casualty probability $p_{\mathrm{a}}$, the physical damage probability $p_{\mathrm{b}}$, and the internal systems failure probability $p_{\mathrm{c}}$. However, the values of $p_{\mathrm{a}}, p_{\mathrm{b}}$, and $p_{\mathrm{c}}$ can be assigned according to the nature of the building and the construction standard for lightning protection (IEC62305, 2006), which are critical for the risk simulations.

\section{Casualty probability}

The casualty probability $\left(p_{\mathrm{a}}\right)$ associated with the touch and step voltage of a lightning stroke to the building depends on the building lightning protection level (LPL), which can be determined as a function of typical protection measures (see IEC62305, 2006, Part 2, p. 105).

\section{Physical damage probability}

The physical damage probability $\left(p_{\mathrm{b}}\right)$ of a building depends on the lightning protection systems (LPS) level and the corresponding protection measures (see IEC62305, 2006, Part 2, p. 107).

3. Internal systems failure probability

A surge protective device (SPD) is designed to protect the internal systems of a building from damage by direct/induced lightning strokes. Accordingly, the internal system failure probability $\left(p_{\mathrm{c}}\right)$ primarily depends on the adopted coordinated SPD protection level (see IEC62305, 2006, Part 2, p. 107).

4. Quantification of a building protective capability

Quantifying the protective capability of buildings by building type is indispensable for model parameterization. To determine the protective capability of various buildings, we have defined the protection measures that are likely to be adopted by 10 building types in Beijing (see Table 1). Most of these buildings are equipped with lightning rods, and some concrete and steel buildings have an iron infra-building and framework as the lead-in wire for lightning protection, and are thus better equipped to protect their occupants from injury by ground lightning stroke. On the other hand, installing LPS and SPD is often required to improve the lightning protection level. Nevertheless, of the 10 building types, only the special houses and general buildings are likely to have possessed LPS protection measures, which would attain LPS I and LPS II-III levels (Table 1), respectively. Fewer buildings have SDP, and thus the capability of protecting material property is unsatisfactory, which explains why most lightning incidents tend to cause physical damage.

\subsection{Estimating the ANDLE of the outdoor area under a building canopy}

The outdoor areas under a building canopy are covered by the lightning collection areas of the nearby buildings (shaded area in Fig. 2). However, the nearby buildings can unintentionally act as lightning rods for the area and intercept the lightning before impact, thereby leading to a very low probability of being struck by lightning stroke at such sites. The ANDLE $N_{\text {Dc }}$ (times year ${ }^{-1}$ ) can be calculated from

$N_{\mathrm{Dc}}=N_{\mathrm{g}} \cdot A_{\mathrm{Dc}} \cdot C_{\mathrm{Dc}} \times 10^{-6}$,

where the collection area $A_{\mathrm{Dc}}\left(\mathrm{m}^{2}\right)$ equals the total collection areas of the buildings subtracted from the areas occupied by the buildings themselves in each grid cell (Fig. 2), and the location factor $C_{\mathrm{Dc}}$ can be estimated from

$$
C_{\mathrm{Dc}}=\frac{h \cdot \sum_{i=1}^{n} S_{\mathrm{buffer}}(i)}{\sum_{i=1}^{n}\left(S_{\mathrm{buffer}}(i) \cdot H(i)\right)},
$$


Table 1. The building types and associated lightning protection measures in Beijing.

\begin{tabular}{|c|c|c|c|c|}
\hline Building type & $\begin{array}{l}\text { GIS } \\
\text { identity } \\
\text { code }\end{array}$ & Protection measure & $\begin{array}{l}\text { Protection measure } \\
\text { to reduce } \\
\text { physical damage }\end{array}$ & SPD level \\
\hline General building & 211 & $\begin{array}{l}\text { Iron infra-building and framework as } \\
\text { a lead-in wire in the building }\end{array}$ & Protected by LPS III & No coordinated SPD protection \\
\hline $\begin{array}{l}\text { General building } \\
\text { with basement }\end{array}$ & 21109 & Same as above & Protected by LPS III & Same as above \\
\hline Bunk house & 212 & Effective soil equipotentialization & Not protected by LPS & Same as above \\
\hline $\begin{array}{l}\text { Hunk house } \\
\text { with basement }\end{array}$ & 21209 & Same as above & Same as above & Same as above \\
\hline Bridge gallery & 218 & $\begin{array}{l}\text { Electrical insulation of } \\
\text { exposed down-conductor }\end{array}$ & Same as above & Same as above \\
\hline Special house & 229 & $\begin{array}{l}\text { Iron infra-building and framework as } \\
\text { a lead-in wire in the building }\end{array}$ & Protected by LPS I & SPD II are designed \\
\hline $\begin{array}{l}\text { Special house } \\
\text { with basement }\end{array}$ & 22909 & Same as above & Same as above & SPD III are designed \\
\hline Ruined house & 214 & No protection measures & Not protected by LPS & No coordinated SPD protection \\
\hline Hut & 215 & Same as above & Same as above & Same as above \\
\hline Public lavatory & 3551 & $\begin{array}{l}\text { Electrical insulation of } \\
\text { exposed down-conductor }\end{array}$ & Same as above & Same as above \\
\hline
\end{tabular}

where $h$ is the constant height of one floor, $H(1), \ldots$, and $H(n)$ are the nearby building heights, and $S_{\text {Buffer }}(1), \ldots$, and $S_{\text {Buffer }}(n)$ are the respective buffer areas, denoting the collection areas of the nearby buildings. Undoubtedly, the areas under the canopy will receive fewer lightning strikes because most of the lightning will be intercepted by nearby tall buildings.

\subsection{Estimating the ANDLE of an open-field area not under a building canopy}

Anything located in an open-field environment is completely exposed to lightning, and thus the lightning risk is much higher than that under a building canopy. The ANDLE $N_{\text {Ds }}$ (times year ${ }^{-1}$ ) is

$N_{\mathrm{Ds}}=N_{\mathrm{g}} \cdot A_{\mathrm{Ds}} \cdot C_{\mathrm{Ds}} \times 10^{-6}$,

where the collection area $A_{\mathrm{Ds}}\left(\mathrm{m}^{2}\right)$ equals the grid-cell area subtracted from the building collection areas in that grid (blank areas in Fig. 2), and the location factor $C_{\text {Ds }}$ can be estimated from the DEM (see Table 2). Apparently the location factor in this situation could be greater than that calculated by Eq. (9).

\section{Implementation of the lightning risk assessment model}

In principle, the ANDLE is an index of causative factors, and the human beings and material properties are the exposure factors. However, the vulnerabilities of human beings and properties to lightning are not identical due to the obvious discrepancy in protective capability, resistance, and loss rate (Holle et al., 1996, 2005; Curran et al., 2000). For risk identification and management, the lightning risk should be subdivided into the casualty risk and the property loss risk and assessed using the following procedures.

\subsection{Lightning casualty risk}

The ANDLE on land surface $N$ is the accumulation of the ANDLEs of the buildings, outdoor areas under a building canopy and open-field areas, which can be obtained from

$$
\begin{aligned}
N & =N_{\mathrm{d}}+N_{\mathrm{Dc}}+N_{\mathrm{Ds}} \\
& =N_{\mathrm{g}} \cdot\left(A_{\mathrm{d}} \cdot C_{\mathrm{d}} \cdot P_{\mathrm{d}}+A_{\mathrm{Dc}} \cdot C_{\mathrm{Dc}}+A_{\mathrm{Ds}} \cdot C_{\mathrm{Ds}}\right) \times 10^{-6} .
\end{aligned}
$$

Herein, the protective capability of a building $P_{\mathrm{d}}$ is equivalent to the casualty probability $p_{\mathrm{a}}$, which is $P_{\mathrm{d}}=p_{\mathrm{a}}$.

Overall, the ANDLE is the product of the CG stroke density $N_{\mathrm{g}}$ and the vulnerability $V$, and thus the vulnerability is

$V=\left(A_{\mathrm{d}} \cdot C_{\mathrm{d}} \cdot P_{\mathrm{d}}+A_{\mathrm{Dc}} \cdot C_{\mathrm{Dc}}+A_{\mathrm{Ds}} \cdot C_{\mathrm{Ds}}\right) \times 10^{-6}$.

The casualty risk in grid cell $R_{\mathrm{p}}$ (persons year ${ }^{-1}$ ) is therefore

$$
\begin{aligned}
R_{\mathrm{p}} & =N \cdot E_{\mathrm{p}}=N_{\mathrm{d}} \cdot l_{\mathrm{t}} \cdot E_{\mathrm{p}, \mathrm{d}}+N_{\mathrm{Dc}} \cdot l_{\mathrm{t}, \text { canopy }} \cdot E_{\mathrm{p}, \text { canopy }} \\
& +N_{\mathrm{Ds}} \cdot l_{\mathrm{t}, \text { space }} \cdot E_{\mathrm{p}, \text { space }},
\end{aligned}
$$

where $E_{\mathrm{p}, \mathrm{d}}, E_{\mathrm{p}, \text { canopy }}$, and $E_{\mathrm{p} \text {,space }}$ are the exposure of the people in the building, outdoor area under a building canopy and open-field area, respectively, $E_{\mathrm{p}}$ is the total population in the grid cell, $N_{\mathrm{d}}, N_{\mathrm{Dc}}$, and $N_{\mathrm{Ds}}$ are the respective ANDLE values for these areas, and $l_{\mathrm{t}}, l_{\mathrm{t} \text {,canopy }}$, and $l_{\mathrm{t} \text {, space }}$ are the 
Table 2. Estimating the open-field area location factor $\left(C_{\mathrm{d}}\right)$ based on surrounding terrain (quoted from IEC62305, 2006).

\begin{tabular}{ll}
\hline The bare space exposure and its sounding & $C_{\mathrm{d}}$ \\
\hline Terrain that is $8 \mathrm{~m}$ higher within a range of $250 \mathrm{~m}$ & 0.7 \\
A 5 m elevation surge (standard deviation) within a range of $250 \mathrm{~m}$ & 1 \\
On the top or ridge of a mountain & 1.5 \\
\hline
\end{tabular}

Table 3. Estimated percentage of the population outdoors through the day.

\begin{tabular}{lllllllll}
\hline $0-5 \mathrm{~h}$ & $5-7 \mathrm{~h}$ & $7-9 \mathrm{~h}$ & $9-12 \mathrm{~h}$ & $12-14 \mathrm{~h}$ & $14-17 \mathrm{~h}$ & $17-19 \mathrm{~h}$ & $19-22 \mathrm{~h}$ & $22-24 \mathrm{~h}$ \\
\hline $0 \%$ & $2 \%$ & $20 \%$ & $10 \%$ & $10 \%$ & $10 \%$ & $5 \%$ & $1 \%$ & $0.5 \%$ \\
\hline
\end{tabular}

respective loss ratios. Here we set $l_{\mathrm{t}, \mathrm{space}}=l_{\mathrm{t}, \mathrm{canopy}}=10^{-4}$ and $l_{\mathrm{t}}=10^{-6}$ (referenced to IEC62305, 2006).

The population density in the classified areas must include estimates of two groups, i.e. those inside and those outside the buildings. These estimates are based on the changing proportion of the population that is outdoors at various times through the day (Table 3). We focused on the indoor or outdoor population between 10:00 and 24:00 local time (LT), because lightning is generally most likely to occur between 12:00 and 22:00 LT in Beijing (Zhou et al., 2009). Additionally, lightning incidents mostly occur between 10:00 and 24:00 LT in Beijing, according to the historical damage reports (Fig. 4).

\subsection{Lightning-related property loss risk}

To estimate the property loss risk, the GDP density is substituted for the exposure, that is

$R_{\mathrm{g}}=N_{\mathrm{g}} \cdot A_{\mathrm{d}} \cdot C_{\mathrm{d}} \cdot P_{\mathrm{d}} \cdot E_{\mathrm{g}} \cdot l_{\mathrm{r}} \times 10^{-6}$,

where $R_{\mathrm{g}}$ (Yuan year ${ }^{-1}$ ) is the property loss risk, $l_{\mathrm{r}}$ is the property loss ratio, and $E_{\mathrm{g}}\left(\right.$ Yuan $\mathrm{km}^{-2}$ ) is the GDP density. The protective capability $P_{\mathrm{d}}$ refers to the physical damage probability $p_{\mathrm{b}}$ and the internal system failure probability $p_{\mathrm{c}}$, which is $P_{\mathrm{d}}=p_{\mathrm{b}}+p_{\mathrm{c}}$, provided that the property is generally under the protection of a building.

The property loss ratio $l_{\mathrm{r}}$ is the ratio of expected damage $\operatorname{loss} C_{1}$ to the asset values threatened by lightning $C$, that is

$l_{\mathrm{r}}=\frac{C_{1}}{C}$,

Given that $C_{1}=R_{\mathrm{g}}$, which indicates that the property loss risk can be substituted for the expected damage loss, Eq. (14) can be rewritten as

$$
\begin{aligned}
& R_{\mathrm{g}}=N_{\mathrm{g}} \cdot A_{\mathrm{d}} \cdot C_{\mathrm{d}} \cdot P_{\mathrm{d}} \cdot E_{\mathrm{g}} \cdot \frac{R_{\mathrm{g}}}{C} \times 10^{-6} \\
& C=N_{\mathrm{g}} \cdot A_{\mathrm{d}} \cdot C_{\mathrm{d}} \cdot P_{\mathrm{d}} \cdot E_{\mathrm{g}} \times 10^{-6} .
\end{aligned}
$$

We can then estimate the asset values threatened by lightning $C$ using Eq. (16), without knowing the loss ratio $l_{\mathrm{r}}$. $C$

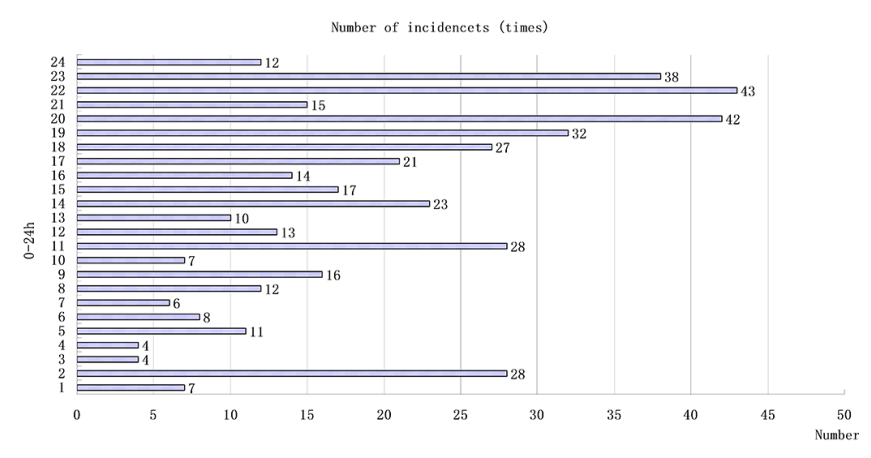

Figure 4. Number of historical lightning incidents occurring hourly in Beijing.

thus denotes the amount of GDP under the threat of lightning based on Eq. (16). However, the damage loss $C_{1}$ can be obtained from the damage reports, and the property loss ratio $l_{\mathrm{r}}$ would be estimated from Eq. (15).

\subsection{Framework of the lightning risk assessment model (LRAM)}

The simulation calculates the average $\operatorname{ANDLE}(N)$, vulnerability $(V)$, lightning casualty risk $\left(R_{\mathrm{p}}\right)$ and property loss risk $\left(R_{\mathrm{g}}\right)$, by the procedure of data deriving, locating, and assessing (Fig. 5). The model depends on the data obtained from (1) the statistical yearbook from which the exposure of population and GDP density is derived, (2) the LLF data for calculating the CG stroke density, (3) the GIS mapping data for locating and classifying the land surface, and (4) the DEM for deducing the location factor. In particular, the ANDLE is calculated from the CG stroke density and vulnerability (based on the protective capability and location factor). Subsequently, the ANDLE overlapping with the population and GDP densities can be used to obtain the lightning casualty risk and property loss risk, respectively. 


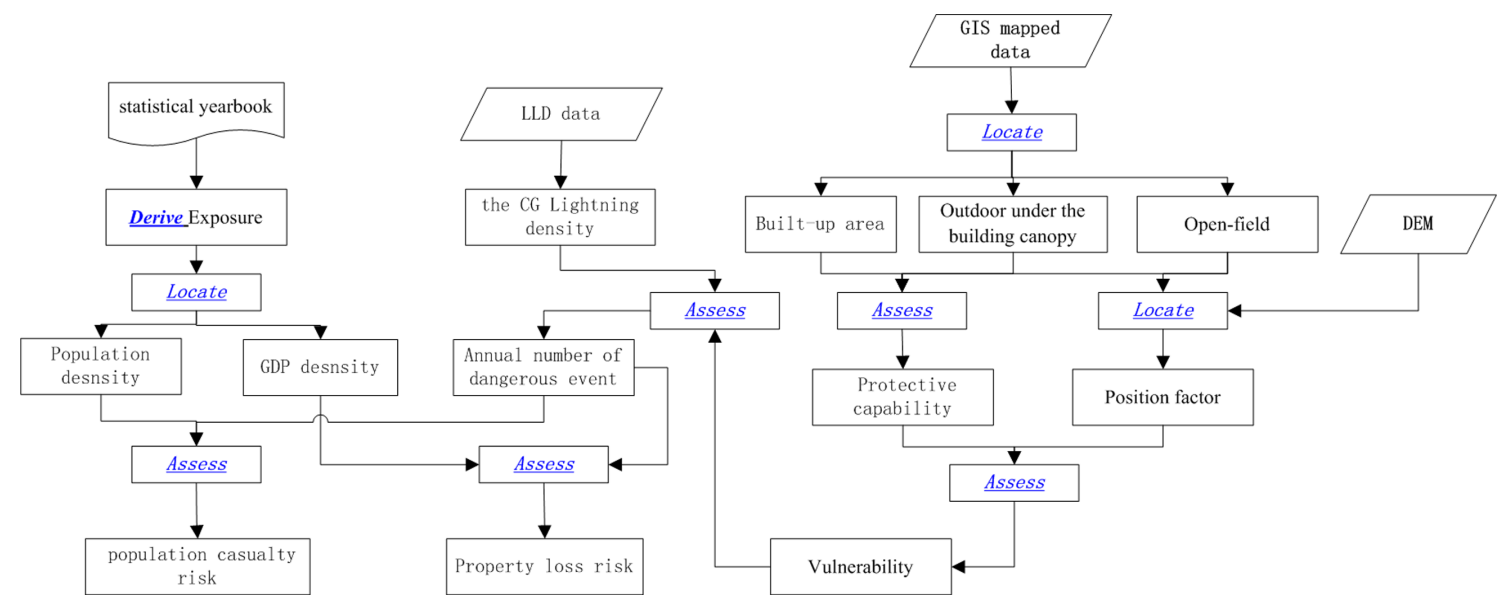

Figure 5. Schematic display of the framework for the lightning risk assessment model.

\section{Risk simulation and analysis}

\subsection{CG flash/stroke density}

Based on the climatological data covering a period of five decades, the annual lightning density in Beijing is 9.59 flashes $\mathrm{km}^{-2}$ year $^{-1}$ (IC and CG combined), calculated using an empirical formula (Price and Rind, 1993) which is approximately equal to that of the global annual lightning density (Christian et al., 2003). The CG flash density ranged from 1.6 to 2.4 flashes $\mathrm{km}^{-2}$ year ${ }^{-1}$, which is 0.2606 of the lightning density (IC and CG combined), corresponding to the climatic characteristics of the lightning activity in a warm temperate zone with a ratio of 2/3 (Zhou et al., 2009).

The CG flash densities derived from lightning location finder data mostly range from 0.5 to 2 flashes $\mathrm{km}^{-2}$ year $^{-1}$, and the peak flash density is 5.78 flashes $\mathrm{km}^{-2}$ year $^{-1}$. Three high-density areas in which the CG flash density is greater than 1.5 flashes $\mathrm{km}^{-2}$ year ${ }^{-1}$ are identified (Fig. 6): the JuMaHe river valley in the southwestern region (A), the ChangPing-ShunYi zone (B), and the PingGu-MiYun zone (C). The reason for high CG flash density along the JuMaHe river valley is that the mountain ranges and rivers spread around the river valley such that moisture is abundant at the bottom of the river valley, resulting in convergence of current flow and convective force, conditionally enhancing the convection (Tao and Zhao, 1993; Zheng et al., 2005; Bogdan and Burcea, 2010). However, the ChangPingShunYi zone is to the north of the Beijing metropolis, downwind of the summer monsoon, which results in a stronger convection (Shepherd et al., 2002; Mote et al., 2007; Stallins and Rose, 2008; Rose et al., 2008). The PingGu-MiYun zone near the BoHai coast is very humid and its spreading mountains also enhance the convection there (Zheng et al., 2005). It is clear that lightning is relatively active in the mountainous rural areas of Beijing.

\subsection{Lightning risk simulated by the model}

\subsubsection{Vulnerability}

The model estimates the vulnerability using Eq. (13), and the result shows that in the mountainous northern and western regions, the vulnerability is still higher than on the plains, where the urban area sprawls out from the centre (Fig. 7). Indeed, in rural and suburban areas, the hilly terrain can readily attract CG lightning due to point charge (Vogt, 2011). In addition, in considering the availability of protection against lightning, finding buildings for immediate sheltering in thunderstorms is relatively difficult in rural areas. Furthermore, few rural dwellings have been equipped with lightning rods. In China, $97 \%$ of lightning fatalities and injuries occur in rural areas (Ma et al., 2008); meanwhile, our historical casualty reports reveal that the rural areas account for $91.3 \%$ of the lightning fatalities and injuries between 2001 and 2010.

\subsubsection{Average annual number of dangerous lightning events}

Calculated using Eq. (12), the overall ANDLE densities are more than 3 times km ${ }^{-2}$ year $^{-1}$, even as high as 9 times $\mathrm{km}^{-2}$ year $^{-1}$ in the mountainous rural areas, but less than 0.3 times $^{-2}$ year $^{-1}$ in urban areas. The high value in the mountainous areas is due to the high CG flash/stroke density and vulnerability (Fig. 8). The ANDLE can be recognized as the causative factor not overlapping with exposure, and evidently it indicates the potential hazard that anything staying in the high-value area is more likely to be struck by lighting flashes/strokes than elsewhere else. For risk management, the significance of the zoning for the ANDLE is that it clarifies where it is prone to be struck by lightning so that the necessary mitigation or protection measures should be adopted to reduce this risk. 


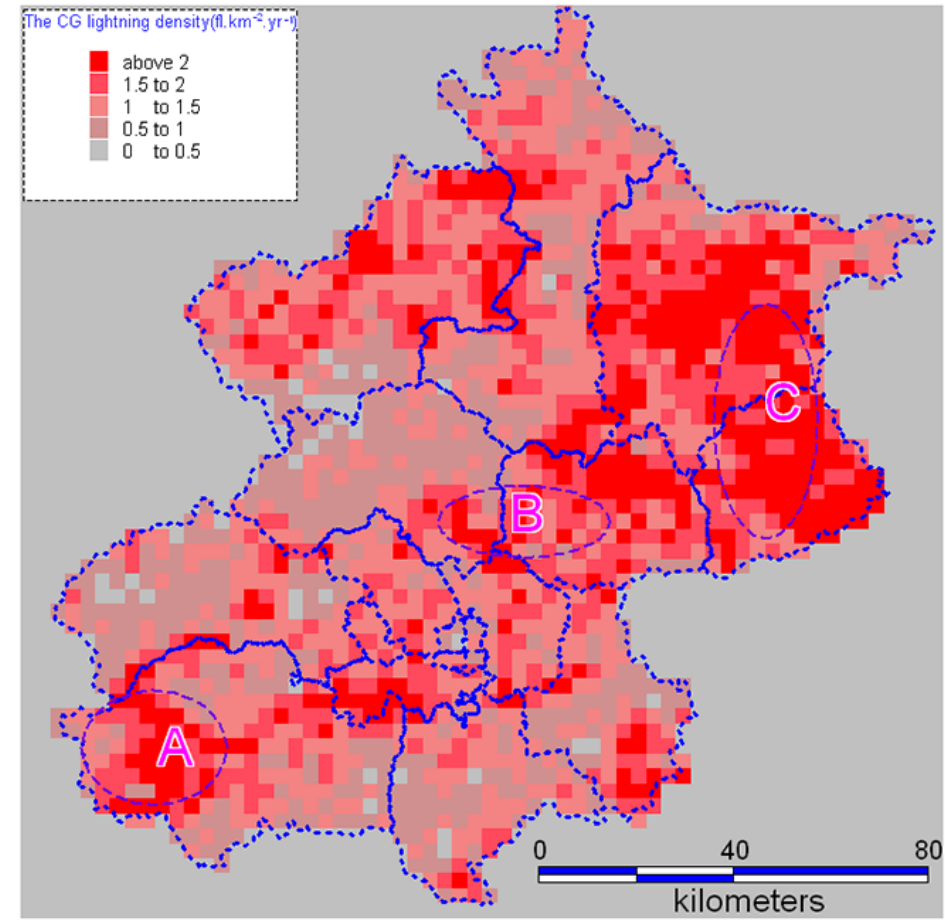

Figure 6. CG flash density distribution map derived from LLF data, highlighting the three high-density areas (A-C) in Beijing.

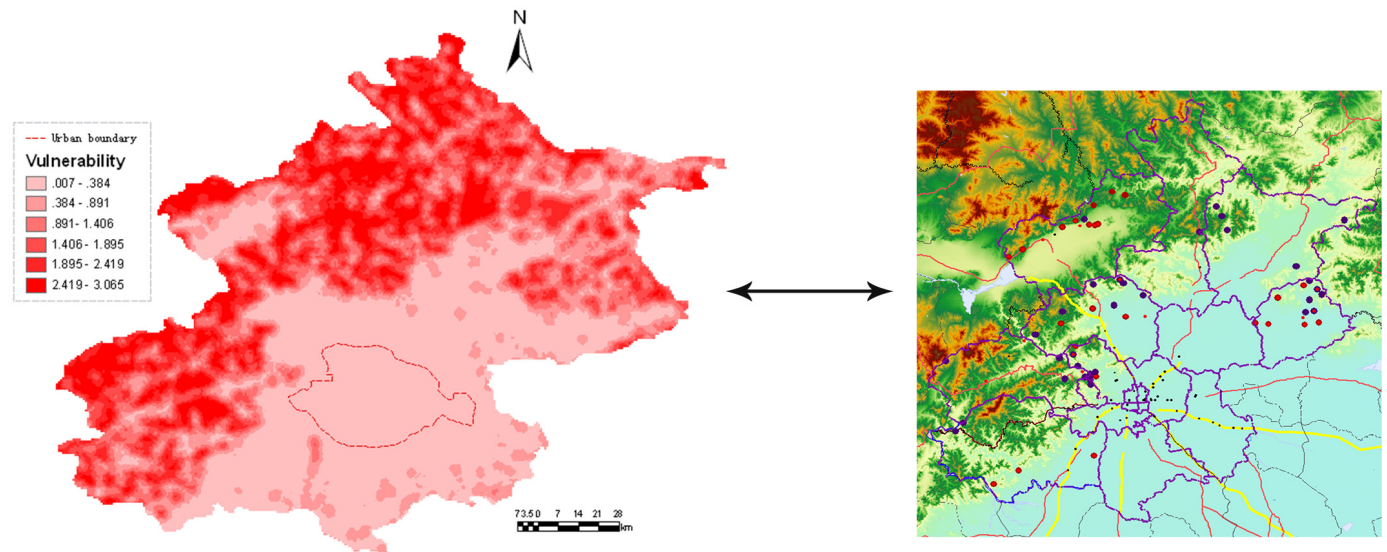

Figure 7. Vulnerability zoning calculated by the model and the corresponding topography in Beijing.

\subsubsection{The lightning casualty risk}

From Eq. (12), the casualty risk value $R_{\mathrm{p}}$ (persons year ${ }^{-1}$ ) is the product of the ANDLE and the population density. The risk simulation demonstrates that even with a high population density, $R_{\mathrm{p}}$ in urban areas is generally lower than that in suburban or rural areas. Moreover, the distribution of high $R_{\mathrm{p}}$ areas significantly corresponds to most of the historical casualty incidents (Fig. 9). In detail, the $R_{\mathrm{p}}$ densities are generally less than 0.00845 persons $\mathrm{km}^{-1}$ year $^{-1}$ in most urban areas, with an estimated return period of nearly 118 years. In most rural areas, $R_{\mathrm{p}}$ densities are more than 0.16867 persons $\mathrm{km}^{-2}$ year $^{-1}$, with a maximum of 0.5876 persons $\mathrm{km}^{-1}$ year $^{-1}$. Naturally, the buildings in urban areas are often concrete and steel buildings equipped with lightning rods, which would be effective in protecting the occupants, and finding a building to be used as a lightning shelter is also easier in these areas, whereas there are sparsely spread buildings in rural areas, most lacking lightning protection measures (Zhang et al., 2011). In addition, in urban areas, many high-rise buildings produce a lightning rod effect, reducing the probability of being struck by direct lightning. Hence, in risk simulation, we set the proportion to the outdoor population on thunderstorm days relatively lower 

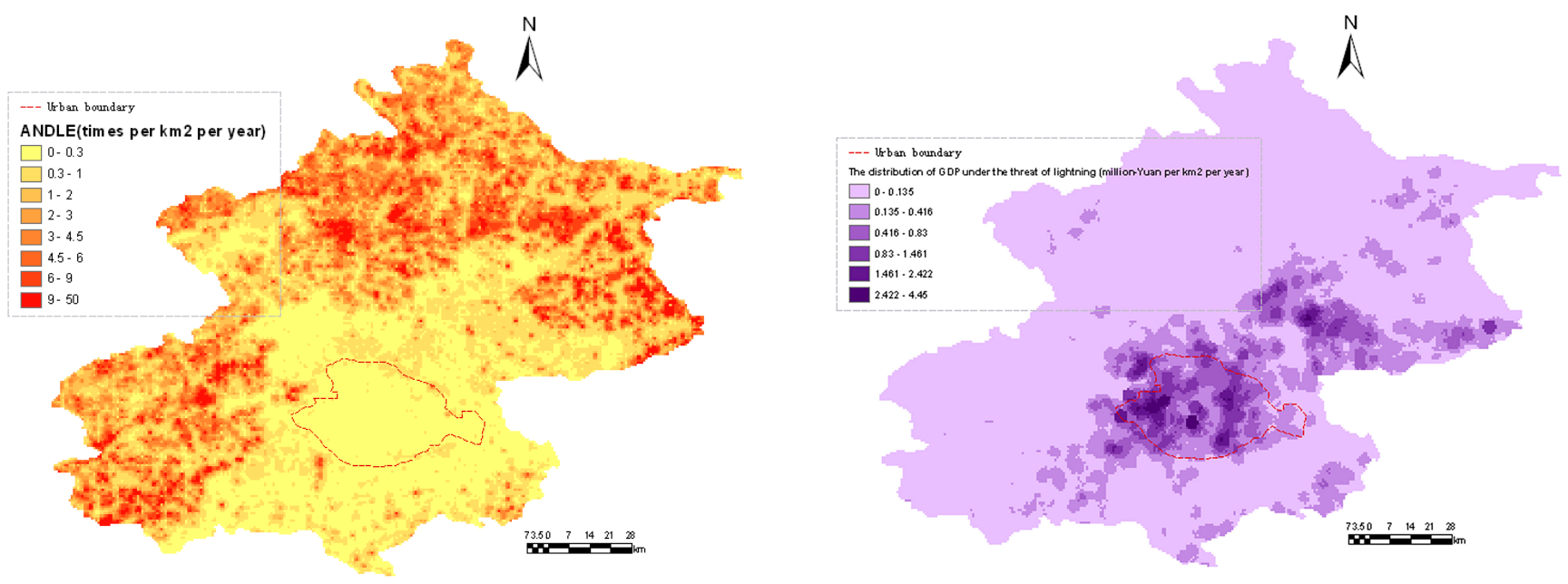

Figure 8. ANDLE zoning simulated by the model.
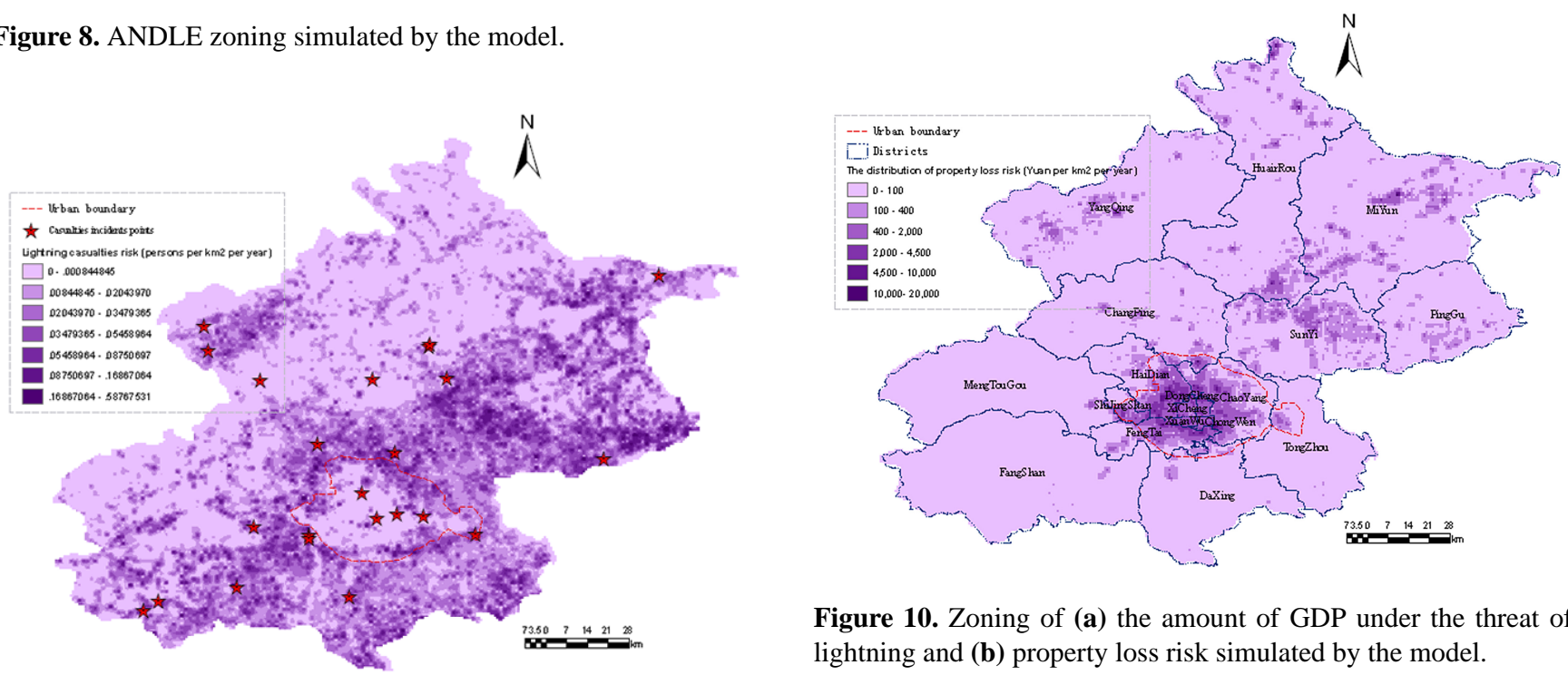

Figure 10. Zoning of (a) the amount of GDP under the threat of lightning and (b) property loss risk simulated by the model.

Figure 9. Zoning of the lightning-related casualty risk simulated by the model and the distribution of historical casualty incidents in Beijing.

in urban areas and assume that the majority of the outdoor population should be under the canopy of its nearby buildings; thus the calculated risk value is lower.

According to historical casualty reports, most lightning fatalities or injuries in suburban or rural areas are those working in open fields, sheltering under trees, riding bicycles, touring in the outskirts, and other activities, which is in accordance with the findings of Holle et al. (1996, 2005), Curran et al. (2000), Wisdom (2009), and Zhang et al. (2011). In addition, it can be perceived that the sum of the casualty risk values $R_{\mathrm{p}}$ estimated by risk simulation is 29.649 persons year $^{-1}$ in Beijing, whereas there are 13 lightning fatalities and 38 injuries from 2001 to 2010 (5.44 annual casualties) in the historical casualty reports. Of course, this discrepancy should be due to uncertainties in the simulation, primarily related to (1) the uncertainty in LLF data

caused by missed lightning detection and positioning error in the lightning location, (2) nonquantitification of factors of the exact locations of human beings, human socio-economic activities and their related behaviours, etc. Moreover, the underreporting of the actual lightning casualties has also contributed to this discrepancy (Lopez et al., 1997; Curran et al., 2000; Zhang, 2011). However, the two values (i.e. the sum of the casualty risk values estimated by risk simulation and the number of annual casualties in historical reports) are not of a large discrepancy in magnitude, which suggests that the casualty risk simulated by the model is somewhat acceptable.

\subsubsection{Property loss risk}

In the simulation of property loss risk, the GDP density is substituted for the exposure to estimate the amount of GDP under the threat of lightning using Eq. (16). The estimated densities are generally greater than Yuan 0.83 million $\mathrm{km}^{-2}$ year $^{-1}$ in urban areas, but less than Yuan 0.135 million $\mathrm{km}^{-2}$ year $^{-1}$ in rural or suburban areas, 
obviously higher in urban areas (Fig. 10a). The sum of these values is Yuan 849.0671 million, while, according to the damage reports, the annual lightning-related loss is Yuan 1.586 million in Beijing, giving a property loss ratio of 0.001868 . The property loss risk can now be calculated using Eq. (14), and its densities are generally greater than 2000 (Yuan $\mathrm{km}^{-2} \mathrm{year}^{-1}$ ) in urban areas, but less than 100 (Yuan $\mathrm{km}^{-2}$ year ${ }^{-1}$ ) in rural or suburban areas (Fig. 10b), differing from that of the casualty risk. This finding can be explained by the high GDP densities in urban areas, where the properties are more vulnerable to lightning, especially of electronic or electrical equipment housed in buildings, which can be destroyed by an induced current or electromagnetic pulse in lightning. Although an LPS and SPD can effectively protect these properties from damage by direct or secondary lightning strikes, these measures rarely become popular even in well-developed urban areas due to their expensiveness. Actually, only the building type of special houses is assigned to an SPD level (see Table 3) in the model simulation.

According to damage reports, most property damage incidents occurred in urban areas (Fig. 11), in agreement with the model simulation, and these incidents were mostly $(86 \%)$ related to electronic, electrical, and transmission equipment damages. The average annual economic loss densities (AAELD, Yuan $\mathrm{km}^{-2}$ year $^{-1}$ ) of the districts in Beijing were obtained from the damage reports (Fig. 12). They indicate that the districts of the central metropolis and other highly urbanized areas usually have a high AAELD, e.g. DongCheng (Yuan $11054 \mathrm{~km}^{-2}$ year $^{-1}$ ) and XuanWu (Yuan $18041 \mathrm{~km}^{-2}$ year $^{-1}$ ); the districts of HaiDian (Yuan $1869 \mathrm{~km}^{-2}$ year $^{-1}$ ) and FengTai (Yuan $4459 \mathrm{~km}^{-2}$ year $^{-1}$ ), partially composed of suburban areas, have lower AAELDs than the highly urbanized districts, and the suburban and rural districts have the lowest values, e.g. YangQing (Yuan $35 \mathrm{~km}^{-2}$ year $^{-1}$ ) and MiYun (Yuan $45 \mathrm{~km}^{-2}$ year $^{-1}$ ). This pattern is in good agreement with the property loss risk simulated by the model. The exception is ShiJingShan, a recognized urban district, its AAELD being Yuan $770 \mathrm{~km}^{-2}$ year ${ }^{-1}$, lower than that of some suburban or even rural districts, such as DaXing (Yuan $932 \mathrm{~km}^{-2} \mathrm{year}^{-1}$ ) and PingGu (Yuan $2685 \mathrm{~km}^{-2}$ year $^{-1}$ ). This is probably because ShiJingShan is primarily occupied by military facilities which do not belong to the municipality, and the damage reports would not cover these facilities. Therefore, the fronted problem is that the reports usually underestimate the lightning loss (Holle et al., 1996, 2005; Zhang et al., 2011) and do not accurately record the actual damage loss, which is critical when estimating the property loss ratio. A comprehensive approach to lightning loss investigation and data collection is thus necessary for uncertainty reduction.

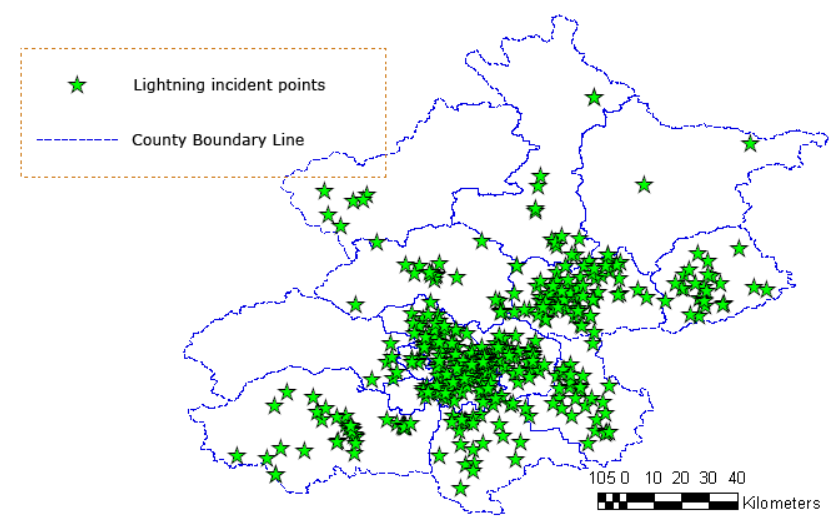

Figure 11. Distribution of lightning incident points between 2001 and 2010 in Beijing.

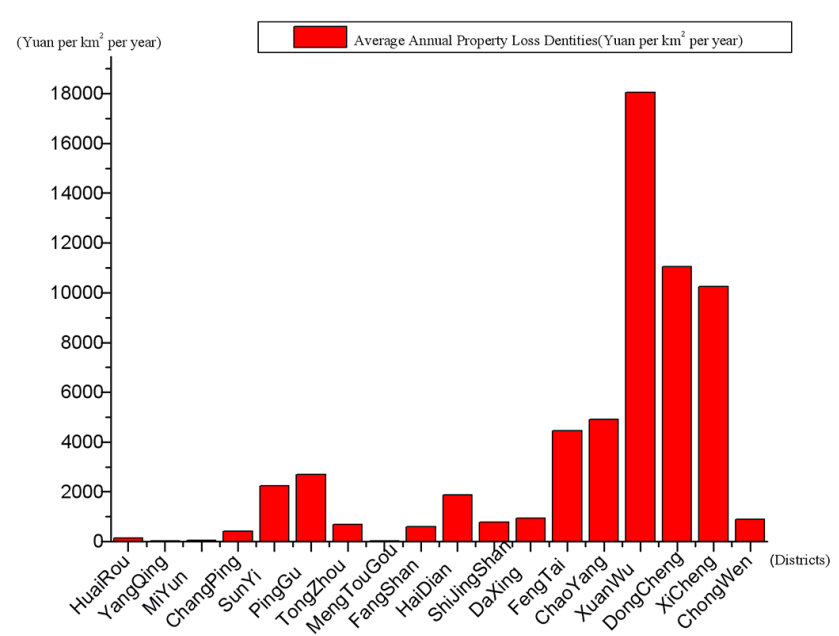

Figure 12. AAELD for the districts of Beijing.

\section{Conclusion}

The CG flash/stroke density derived from LLF data rationally reflects the regional lightning activity around Beijing, and three relatively high CG flash density zones have been identified, all in rural areas. In contrast, the CG flash density converted from the annual number of thunder days is unsuitable for lightning risk assessment because of its low resolution and data uncertainty.

The ANDLE and vulnerability determined by the susceptibility to lightning on land surfaces were estimated based on classifying the land surfaces into buildings, outdoor areas under a building canopy and open-field areas. This approach allows for the straightforward location of these areas and confirms the protective capability of individual buildings, and can be accomplished using a GIS platform. We found that in the mountainous northern or western areas, the vulnerability is higher than in urban areas, because the mountainous terrain in rural areas readily attracts lightning and rural dwellings typically lack protection measures. Also, the 
estimated ANDLE is higher in rural areas. The significance of the ANDLE zoning is that it clarifies those areas most likely to be threatened by lightning, which is important for risk management.

The lightning risk was subdivided into the casualty risk and the property loss risk, on the basis of the discrepancy in protective capability, resistance and loss rate associated with people and property. The casualty risk was assessed from the product of the ANDLE and the population density. Despite the high population density in urban areas, this risk value is generally lower in urban than in rural areas, and this agrees with the distribution of the historical casualty incidents. This finding can be explained by the better protective capability of the buildings and ease of sheltering on thunderstorm days in urban areas, as well as the lightning rod effect produced by high-rise buildings.

In the simulation of property loss risk, the amount of GDP under the threat of lightning needs to be calculated first. The property loss ratio is defined as the ratio of lightning-related loss to the amount of GPD under the threat of lightning, but its estimation would bring about uncertainty, because the damage reports usually underestimate the lightning losses, and a more comprehensive collection of loss data is needed if this uncertainty is to be reduced. Nevertheless, with this property loss ratio, the risk assessment of property loss can be accomplished and the result indicates that these risk values are generally greater in urban than in rural or suburban areas, due to property aggregation in urban areas and vulnerability of material properties to lightning. According to the damage reports, most of the property damage incidents occur in urban areas, and the values of AAELD remain high among urban districts, which corresponds to the distribution of the property loss risk simulated by the model.

Acknowledgements. This study has been supported by the National Natural Science Foundation of China (project 41175099) and the Beijing Natural Science Foundation of China (project 8142019). The authors are also pleased to thank the reviewers for their comments and suggestions, which have been essential for improving the manuscript, its clarity and readability.

Edited by: G. Panegrossi

Reviewed by: three anonymous referees

\section{References}

Ait-Amar, S. and Berger, G.: Lightning interception on elevated building, in: Proceedings of the 5th WSEAS Int. Conf. on Power Systems and Electromagnetic Compatibility, 23-25 August 2005, WSEAS, Corfu, Greece, 17-23, 2005.

Anderson, G. and Klugmann, D.: A European lightning density analysis using 5 years of ATDnet data, Nat. Hazards Earth Syst. Sci., 14, 815-829, doi:10.5194/nhess-14-815-2014, 2014.

Ashley, W. S. and Gilson, C. W.: A reassessment of US lightning mortality, B. Am. Meteorol. Soc., 90, 1501-1518, 2009.
Baker, M. B.: Relationships between lightning activity and various thundercloud parameters: satellite and modeling studies, Atmos. Res., 51, 221-236, 1999.

Bertram, I. and Mayr, G. J.: Lightning in the eastern Alps 19931999, part I: Thunderstorm tracks, Nat. Hazards Earth Syst. Sci., 4, 501-511, doi:10.5194/nhess-4-501-2004, 2004.

Biagi, C. J., Cummins, K. L., Kehoe, K. E., and Krider, E. P.: National lightning detection network (NLDN) performance in southern Arizona, Texas, and Oklahoma in 2003-2004, J. Geophys. Res., 112, D05208, doi:10.1029/2006JD007341, 2007.

Bogdan, A. and Burcea, C.: A cloud-to-ground lightning climatology for Romania, Mon. Weather Rev., 138, 579-591, doi:10.1175/2009MWR2975.1, 2010.

Bovalo, C., Barthe, C., and Bègue, N.: A lightning climatology of the South-West Indian Ocean, Nat. Hazards Earth Syst. Sci., 12, 2659-2670, doi:10.5194/nhess-12-2659-2012, 2012.

BusinessDictionary.com, http://www.businessdictionary.com/ definition/gross-domestic-product-GDP.html, (last access: 18 July 2014), 2014.

Changnon, S. A.: Relationships between thunderstorms and cloudto-ground lightning in the United States, J. Appl. Meteorol., 32, 88-105, 1992.

Christian, H. J., Blakeslee, R. J., Boccippio, D. J., Boeck, W. L., Buechler, D. E., Driscoll, K. T., Goodman, S. J., Hall, J. M., Koshak, W. J., Mach, D. M., and Stewart, M. F.: Global frequency and distribution of lightning as observed from space by the Optical Transient Detector, J. Geophys. Res., 108, 4005, doi:10.1029/2002JD002347, 2003.

Cummins, K. L. and Murphy, J. M.: An overview of lightning locating systems: history, techniques, and data uses, with an in depth look at the US NLDN, IEEE T. Electromagn. C., 51, 499-518, 2009.

Cummins, K. L., Cramer, J. A., Biagi, C. J., Krider, E. P., Jerauld, J., Uman, M. A., and Rakov, V. A.: The U.S. National Lightning Detection Network: Post-upgrade status, in: 2nd Conference on Meteorological Applications of Lightning Data, AMS Annual Meeting, Atlanta, available at: https://ams.confex.com/ ams/pdfpapers/105142.pdf, last access: 31 January 2013, 2006.

Curran, E. B., Holle, R. L., and Lopez, R. E.: Lightning casualties and damages in the United States from 1959 to 1994, J. Climate, 13, 3448-3464, 2000.

Elsom, D. M.: Deaths caused by lightning in England and Wales, 1852-1990, Weather, 48, 83-90, 1993.

Elsom, D. M.: Deaths and injuries caused by lightning in the United Kingdom: Analyses of two databases, Atmos. Res., 56, 325-334, 2001.

Fuquay, D. M., Baughman, R. G., Taylor, A. R., and Hawe, R. G.: Characteristics of seven lightning discharges that caused forest fires, J. Geophys. Res., 72, 6371-6373, doi:10.1029/JZ072i024p06371, 1967.

Gabriel, K. R. and Changnon, S. A.: Temporal features in thunder days in the United States, Climatic Change, 15, 455-477, 1989.

Garrick, B. J.: The use of risk assessment to evaluate waste disposal facilities in the United States of America, Safety Sci., 40, 135151, 2002.

Holle, R. L., Lopez, R. E., Arnold, L. J., and Endres, J.: Insured lightning-caused property damage in three western states, J. Appl. Meteorol., 35, 1344-1351, 1996. 
Holle, R. L., López, R. E., and Navarro, B. C.: Deaths, injuries, and damages from lightning in the United States in the 1890s in comparison with the 1990s, J. Appl. Meteorol., 44, 1563-1573, 2005.

IEC62305 - The technical committee of the International Electrotechnical Commission: Protection against lightning, IEC, Geneva, Switzerland, 2006.

Kaplan, S. and Garrick, B. J.: On the quantitative definition of risk, Risk Anal., 1, 11-27, 1981.

Lopez, R. E. and Holle, R. L.: Changes in the number of lightning deaths in the United States during the twentieth century, J. Climate, 11, 70-77, 1997.

Lopez, R. E., Holle, R. L., Watson, A. I., and Skindlov, J.: Spatial and temporal distributions of lightning over Arizona from a power utility perspective, J. Appl. Meteorol., 36, 825-831, 1997.

Ma, M., Lu, W., Zhang, Y., Meng, Q., and Yang, J.: Characteristics of lightning exposure in China from 1997 to 2006, Chinese J. Appl. Meteorol. Sci., 19, 393-400, 2008.

Meyer, V., Sebastian Scheuer, S., and Haase, D.: A multicriteria approach for flood risk mapping exemplified at the Mulde river, Germany, Nat. Hazards, 48, 17-39, 2009.

Mote, T. L., Lacke, M. C., and Shepherd, J. M.: Radar signatures of the urban effect on precipitation distribution: a case study for Atlanta, Georgia, Geophys. Res. Lett., 34, L20710, doi:10.1029/2007GL031903, 2007.

Orville, R. E. Jr.: An analytical solution to obtain the optimum source location using multiple direction finders on a spherical surface, J. Geophys. Res., 92, 10877-10886, 1987.

Petrov, N. I. and D'Alessandro, F.: Assessment of protection system positioning and models using observations of lightning strikes to structures, Proc. R. Soc. Lond. A, 458, 723-742, doi:10.1098/rspa.2001.0906, 2002.

Price, C. and Rind, D.: What determines the cloud-to-ground lightning fraction in thunder-storms?, Geophys. Res. Lett., 20, $463-$ 466, doi:10.1029/93GL00226, 1993.

Renn, O.: Three decades of risk research: accomplishments and new challenges, J. Risk Res., 1, 49-71, 1998.
Rizk, F. A. M.: Modelling of lightning incidence to tall structures, part II, application, IEEE T. Power Deliver., 9, 172-193, 1994.

Rose, L. S., Stallins, J. A., and Bentley, M. L.: Concurrent cloud-toground lightning and precipitation enhancement in the Atlanta, Georgia (United States), urban region, Earth Interact., 12, 1-30, doi:10.1175/2008EI265.1, 2008.

Shepherd, J. M., Pierce, H., and Negri, A. J.: Rainfall modification by major urban areas: observations from spaceborne rain radar on the TRMM satellite, J. Appl. Meteorol., 41, 689-701, 2002.

Smith, K.: Environmental Hazards: Assessing Risk and Reducing Disaster, 2nd Edn., Routledge, New York, USA, 1996.

Stallins, J. A. and Rose, L. S.: Urban lightning: current research, methods, and the geographical perspective, Geography Compass, 2, 620-639, doi:10.1111/j.1749-8198.2008.00110.x, 2008.

Tao, S. and Meng, Q.: Evaluation of ground stroke density distribution and lightning detection efficiency in Beijing-Tianjin-Hebei area, Acta Meteorol. Sin., 10, 346-335, 1996.

Tao, Z. and Zhao, X.: Climatological analysis of lightning in Beijing-TianJin-HeBei District, Acta Meteorol. Sin., 51, 325332, 1993.

Vogt, B. J.: Exploring cloud-to-ground lightning earth highpoint attachment geography by peak current, Earth Interact., 15, 1-16, 2011.

Williams, E. R.: Lightning and climate: a review, Atmos. Res., 76, 272-287, 2005.

Wisdom, M. D.: Lightning fatalities in Swaziland: 2000-2007, Nat. Hazards, 50, 179-191, 2009.

Zhang, W., Meng, Q., Ma, M., and Zhang, Y.: Lightning casualties and damages in China from 1997 to 2009, Nat. Hazards, 57, 465476, 2011.

Zheng, D., Meng, Q., Lu, W., Zhang, Y., Chai, X., and Ma, M.: Spatial and temporal characteristics of cloud-to-ground lightning in summer in Beijing and its circumambience regions, Chinese J. Appl. Meteorol. Sci., 16, 638-664, 2005.

Zhou, Y., Zhang, J., and Sun, L.: Statistic analysis on cloundto-ground lightning characteristics 5 over Beijing, Tianjin and Hebei Province, J. Catastrophology, 24, 101-104, 2009. 